\title{
Movement patterns and home ranges of a pelagic carangid fish, Caranx crysos, around a petroleum platform complex
}

\author{
Harmon Brown $^{1,5, *}$, Mark C. Benfield ${ }^{1}$, Sean F. Keenan ${ }^{2}$, Sean P. Powers ${ }^{3,4}$ \\ ${ }^{1}$ Department of Oceanography and Coastal Sciences, School of the Coast and Environment, Louisiana State University, \\ 2179 Energy, Coast \& Environment Building, Baton Rouge, Louisiana 70803, USA \\ ${ }^{2}$ Florida Fish and Wildlife Conservation Commission, Fish and Wildlife Research Institute, 100 Eighth Avenue SE, \\ St. Petersburg, Florida 33701, USA \\ ${ }^{3}$ Department of Marine Sciences, University of South Alabama, 307 University Blvd., Mobile, Alabama 36688, USA \\ ${ }^{4}$ Dauphin Island Sea Lab, 102B Bienville Boulevard, Dauphin Island, Alabama 36528, USA
}

${ }^{5}$ Present address: Office of Coastal Management, Louisiana Department of Natural Resources, 617 N. Third St./10th Floor, Baton Rouge, Louisiana 70802, USA

\begin{abstract}
Quantification of the movements and home ranges of highly mobile marine species is a challenging prerequisite for a more complete understanding of their ecology. Caranx crysos is a pelagic carangid found in large schools over the mid-shelf of the northern Gulf of Mexico. Twentythree C. crysos were surgically implanted with acoustic transmitters, and their positions were localized around a petroleum platform complex in the Gulf of Mexico using a hydrophone network. Fish were tracked during August 2005 for 23 d, and home ranges were calculated for individual fish over the daily, diel, and entire study period. Most fish showed a preference for a discrete area within the platform complex: 11 fish had a range centroid near one platform for at least $7 \mathrm{~d}$, and 9 fish had a range centroid near one platform for at least $3 \mathrm{~d}$. Only 3 fish showed no preference for a particular site within the platform complex. Mean core daily range varied from 373 to $2202 \mathrm{~m}^{2}$, while the $95 \%$ daily range was between 3082 and $14333 \mathrm{~m}^{2}$. Evidence for diel differences in habitat use was also apparent. Hydrophones detected more transmissions during the day than during the night; however, only 3 fish had significantly larger home ranges during the day than during the night. There was a significant correlation between fish length and both the size of their overall core home range and the size of the $95 \%$ daily home range. Our results suggest that this schooling pelagic species establishes a home range in the vicinity of structure.
\end{abstract}

KEY WORDS: Home range · Caranx crysos · Petroleum platforms · Gulf of Mexico · Movement · Carangidae $\cdot$ Acoustic telemetry

\section{INTRODUCTION}

Historically, little information has been reported on the movements and behaviors of schooling pelagic marine fishes other than tuna (e.g. Block et al. 2005, Domeier et al. 2005). This is not surprising given the technical difficulties of unobtrusively tracking highly mobile fishes in open water. One of the many questions that has not been addressed is whether schooling pelagic fishes display fidelity towards any particular area or location (i.e. home range). Burt (1943) defined the home range of an organism as 'that area traversed by the individual in its normal activities of food gathering, mating, and caring for young'. Occasional forays outside that area, perhaps exploratory in nature, should not be considered part of the home range. In 
order to exclude occasional forays that animals make outside their normal area of activity, the home range is usually considered to be an area where an animal spends $95 \%$ of its time, though this definition is arbitrary and may be related to the p-value of 0.05 in statistical judgments (Powell 2000). While the advantages of having a home range have not been studied empirically, Kramer \& Chapman (1999) suggested that increased utilization of the foraging area, protection of favorable breeding sites, and predator refugia may be reasons for animals having a home range. They cautioned that by staying within a home range the animal may be forgoing the opportunity to discover higher quality habitats.

Most research on the home range of fishes has focused on freshwater taxa (Lyons \& Lucas 2002), reefassociated fishes (Holland et al. 1996, Zeller 1997, Eristhee \& Oxenford 2001), seagrass or kelp bedassociated fishes (Topping et al. 2005, Jadot et al. 2006), and demersal fishes (Lembo et al. 2002, Jorgensen et al. 2006, Schroepfer \& Szedlmayer 2006, Tolimieri et al. 2009). Measurement of home ranges for pelagic fishes does not appear to have been examined. This is likely due to the general migratory nature of most pelagic fishes. We do know that pelagic fishes periodically encounter natural or artificial structures in the open ocean; however, it is uncertain whether they establish home ranges and display site fidelity near such structures. Petroleum platforms are one such example of artificial structures.

There are over 4000 petroleum platforms in the northern Gulf of Mexico (Gulf) (MMS 2007). Clay, silt, or sand substrates predominate in the northern Gulf, and platforms have been estimated to increase the total reef habitat by $27 \%$ (Gallaway \& Lewbel 1982). As platforms are decommissioned, some are completely removed, but many are converted to reefs via the Rigs-to-Reefs program, which is designed to create additional permanent reef habitat in the Gulf (Kasprzak 1998).

Blue runner Caranx crysos is a schooling, pelagic carangid commonly observed near Gulf petroleum platforms where it can be observed feeding in large surface schools during the day. Visual surveys conducted around Gulf platforms from 1970 to 1974 indicated that $C$. crysos was the only species of fish consistently present (Hastings et al. 1976). Surveys conducted by divers and remotely operated vehicles (ROVs) around petroleum platforms found blue runner abundances to be variable, averaging $20 \%$ of all species, with a high of $45.3 \%$ (Stanley \& Wilson 1997). Blue runner feed on zooplankton and micronekton and, in turn, are consumed by larger predatory species, such as king mackerel Scomberomorus cavalla, barracuda Sphyraena barracuda, amberjack Seriola dumerili, cobia Rachycentron canadum, and various tuna and grouper species (McKenney et al. 1958, Keenan et al. 2007).

The only previous research on the home range of carangids appears to be the study of the reefassociated Caranx melampygus by Holland et al. (1996). Acoustic telemetry demonstrated that C. melampygus exhibited consistent diel movements within a measurable home range. Given observed affinities of blue runner for petroleum platforms, it is possible that C. crysos may also establish home ranges near such structures. Given the trophic importance of blue runner in pelagic communities in and around petroleum platforms, quantification of their movement patterns and habitat use during both day and night is necessary to understand their predatory effect on zooplankton and micronekton as well as their spatiotemporal availability to piscivorous predators. In this paper we examine the movement patterns and home ranges of acoustically tagged blue runner in the vicinity of an offshore petroleum platform complex in the northern Gulf.

\section{MATERIALS AND METHODS}

Study site. The study was conducted from Chevron's South Timbalier 151 (ST151) platform complex $\left(28^{\circ} 37.000^{\prime} \mathrm{N}, 90^{\circ} 15.367^{\prime} \mathrm{W}\right)$. ST151 is a series of 6 platforms connected by catwalks located approximately $50 \mathrm{~km}$ south of Port Fourchon, Louisiana, USA, in water at a depth of $43 \mathrm{~m}$ (Fig. 1). Such complexes of platforms are fairly common throughout the world's offshore oil fields.

Acoustic localization system. We employed an 8-channel acoustic tracking system (MAP_600, Lotek Wireless) that was mounted in temporary lab space on ST151 and linked via cables to underwater hydrophones (LHP-1, Lotek Wireless). The use of a cabled system enabled the hydrophones to be temporally synchronized and allowed for precise positioning solutions based on delays among signal times of arrival. The hydrophones were mounted on polyvinyl chloride (PVC) brackets suspended via tensioned $6.35 \mathrm{~mm}$ stainless steel cables and were placed at depths between 5 and $15 \mathrm{~m}$. By 1 August 2005, 8 hydrophones had been installed beneath ST151 (Fig. 1C). The system was operational for $23 \mathrm{~d}$ from 5 to 27 August 2005, when the study was terminated prematurely due to Hurricane Katrina. During operation, the system recorded detections continually except for a 5 to $10 \mathrm{~min}$ interval each morning when the previous day's data were transferred to a laptop. Non-networked sentinel hydrophones (LHP-1 Lotek Wireless) connected to receivers (MAP-RT, Lotek Wireless) were mounted 

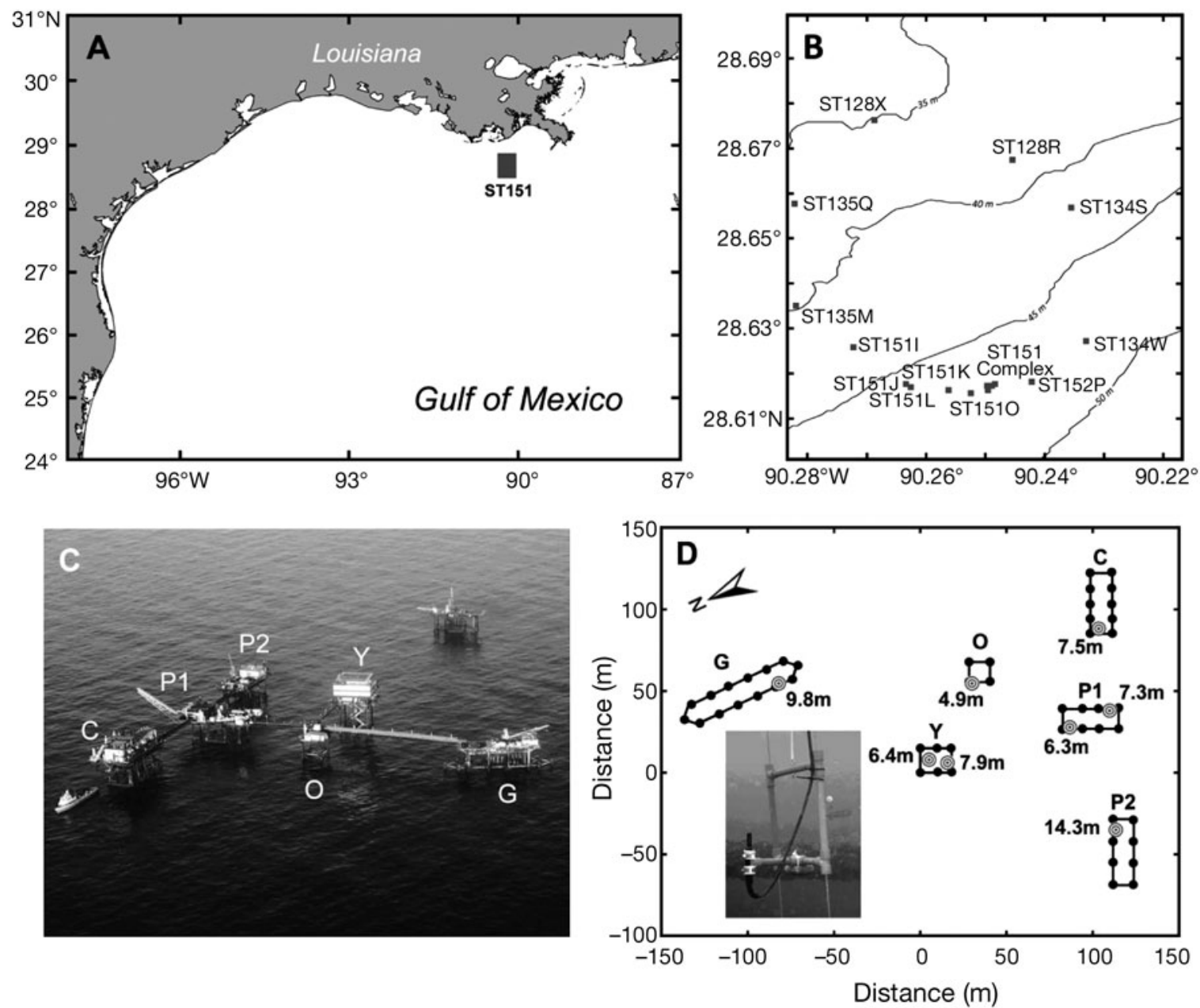

Fig. 1. (A) Location of the study site (shaded rectangle) in relation to northern Gulf of Mexico. (B) The ST151 complex is located on the southern edge of a ring of unmanned platforms. (C) An aerial photo of the complex viewed from the east. (D) The 6 platforms that make up ST151 with their pilings indicated by black circles. G = G-Deck, O = Old Quarters, Y = Yankee, C = Compressor, P1 = Production One, P2 = Production Two. (๑) Locations of the 8 hydrophones that were linked to a receiver on Old Quarters. Hydrophone depths are indicated next to each location

on 3 unmanned platforms (ST134S, ST135M, and ST151K) to detect excursions away from the main complex (Fig. 1).

Acoustic tags. We used cylindrical acoustic tags (CTP_M11_12, Lotek Wireless) that were $11 \mathrm{~mm}$ in diameter and $46 \mathrm{~mm}$ long with a mass of $8.2 \mathrm{~g}$. Each tag transmitted an identity code at $76 \mathrm{kHz}$ encoded within a single ping. The tags used code division multiple access (CDMA), which allows for simultaneous sub-meter positioning of multiple individuals with a low signal-to-noise ratio (Niezgoda et al. 2002). Tags were set to transmit at either $0.25 \mathrm{~Hz}$ or $0.5 \mathrm{~Hz}$ with estimated lifespans of 30 and $10 \mathrm{~d}$, respectively. Two different transmit intervals were selected to allow some fish to be monitored for extended periods while providing more frequent localization of others. All tags were equipped with temperature and pressure sen- sors, and these data were transmitted on alternating pings along with the identity number.

Surgical implantation of tags. Fish were collected using lures with barbless hooks in order to minimize physical trauma. Intraperitoneal implantation of acoustic tags followed the method of Meyer \& Honebrink (2005), though tissue adhesive was not used. Following surgery each fish was placed in a holding tank containing oxygenated seawater until the fish recovered equilibrium. The fish was then transferred to a holding pen suspended beneath the Yankee platform (Fig. 1) for observation before release. All fish except the first one, which was released following initial recovery of equilibrium, were held for at least $8 \mathrm{~h}$ in the holding pen. Fish were released in groups each morning to reduce predatory mortality. No fish died or appeared to be in distress after $8 \mathrm{~h}$ in the holding pen. Between 5 and 
15 August 2005, we released 33 blue runner with $0.25 \mathrm{~Hz}$ tags and 13 with $0.5 \mathrm{~Hz}$ tags.

Data analysis. Telemetry data were imported into BioMAP software (Lotek Wireless) for processing. BioMAP performs the localization of the tag transmission data recorded by the MAP_600 system to estimate the 2 -dimensional positions of each tag. We recognize that the true location of each fish includes a depth component and that ignoring this component introduced some error into each localization. We estimate that our 2D position estimates introduced, at the very most, errors of $\pm 0.16 \mathrm{~m}$ during the day and $\pm 1.04 \mathrm{~m}$ at night. Positional data were filtered for mathematical stability, degrees of freedom, and accuracy using BioMAP metrics, with outliers being eliminated. The remaining data were subsequently filtered to remove swimming speeds greater than 20 body lengths $\mathrm{s}^{-1}$, a maximum likely swimming velocity determined by a review of published swimming studies (e.g. Robinson \& Pitcher 1989, Hymel et al. 2002, Baltz et al. 2005, Blake et al. 2005).

Filtered data were imported into ArcMap 9.2 (ESRI), and the home range of each fish was calculated using the Home Range Extension. Fixed kernel home range estimation was calculated using least-squares crossvalidation. The areas where blue runner spent $50 \%$ (core home range) and $95 \%$ (95\% home range) of their time were estimated. Pearson's product moment correlation was calculated using the fork length (FL) and size of the ranges using MATLAB.

Data were examined for differences between the daytime (local sunrise $+30 \mathrm{~min}$ to local sunset $-30 \mathrm{~min}$ ) and nighttime (sunset $+30 \mathrm{~min}$ to sunrise $-30 \mathrm{~min}$ ) home ranges. Sunrise and sunset times at ST151 were obtained from the US Naval Observatory. Differences in the sizes of the daytime and nighttime ranges were tested for normality using a Jarque-Bera test (Jarque \& Bera 1980) and for homogeneity of variance using an F-test in MATLAB. If the data were both normally distributed and showed homogeneity of variance, then a 2 -tailed paired $t$-test ( $\alpha=0.05$ ) was run to test for differences in size of the home range; otherwise, a Mann-Whitney $U$-test ( $\alpha=0.05$ ) was run using the Statistics for Research \& Analysis Software Package (SPSS, SPSS Inc.). The successive day/night samples for individual fish were used as replicates for the paired $t$ - or Mann-Whitney $U$-tests. A general linear model was run to compare the sizes of the day and night home range areas at the population level for all tagged fish using SPSS. A multivariate general linear model was performed using SPSS to evaluate rela- tionships between the areas of the daily home ranges for all tagged fish and the categorical variables: individual fish and day of year including an interaction term.

\section{RESULTS}

\section{Localizations}

Of the 46 tagged Caranx crysos, 23 were tracked for at least 7 consecutive days (Fig. 2, Table 1). Consecutive days refer to at least one valid position solution obtained in a $24 \mathrm{~h}$ period, although in almost all cases, many more valid position solutions were obtained. All subsequent results refer to these 23 individuals, which ranged in size from 267 to $338 \mathrm{~mm}$ FL and from 397 to $600 \mathrm{~g}$ (Table 1).

All 23 blue runner were localized daily over a continuous period (Fig. 2), except Fish 32700, which disappeared on 18 August and returned on 25 August; Fish 33000, which was not localized on 16, 19, and 21 to 22 August; and Fish 34300, which was not localized on 15 to 17 August and 19 to 22 August. Nine of the fish (30200, 30500, 30600, 32500, 32700, 33000, 33700, 34200, and 34300) were not localized during some nights, but were detected after sunrise on the next day. The percentage of transmission detections that produced valid localization estimates was higher during the day than at night (Fig. 3). Overall, the number of times an individual fish was localized at the platforms during the day versus the night was significantly higher for all but 6 of the tagged fish on the basis of paired $t$-tests. Localization frequencies for the remaining 6 fish $(29500,30200,30500,31300,34000$, and 34600) did not differ between day and night.

None of the fish that were tagged and released at the ST151 complex were detected by the sentinel hydrophones deployed at 3 of the surrounding unmanned

Table 1. Caranx crysos. Identity codes, fork length (FL), mass, and the maximum consecutive days at liberty of 23 tagged blue runner that were tracked for at least $7 \mathrm{~d}$ around ST151 in August 2005

\begin{tabular}{|c|c|c|c|c|c|c|c|}
\hline $\begin{array}{l}\text { Tag ID } \\
\text { code }\end{array}$ & $\begin{array}{c}\text { FL } \\
(\mathrm{mm})\end{array}$ & $\begin{array}{l}\text { Mass } \\
(\mathrm{g})\end{array}$ & $\begin{array}{l}\text { Days } \\
\text { tracked }\end{array}$ & $\begin{array}{l}\text { Tag ID } \\
\text { code }\end{array}$ & $\begin{array}{c}\mathrm{FL} \\
(\mathrm{mm})\end{array}$ & $\begin{array}{l}\text { Mass } \\
\text { (g) }\end{array}$ & $\begin{array}{l}\text { Days } \\
\text { tracked }\end{array}$ \\
\hline 29500 & 282 & 407 & 13 & 33300 & 291 & 407 & 20 \\
\hline 30200 & 294 & 442 & 16 & 33500 & 278 & 486 & 13 \\
\hline 30500 & 299 & 462 & 15 & 33700 & 275 & 392 & 16 \\
\hline 30600 & 286 & 405 & 15 & 33800 & 290 & 390 & 21 \\
\hline 30800 & 304 & 403 & 13 & 34000 & 375 & 600 & 19 \\
\hline 31300 & 338 & 600 & 20 & 34200 & 283 & 408 & 20 \\
\hline 31800 & 316 & 482 & 20 & 34300 & 285 & 375 & 23 \\
\hline 32100 & 288 & 493 & 18 & 34600 & 303 & 527 & 18 \\
\hline 32500 & 298 & 455 & 20 & 34800 & 283 & 392 & 18 \\
\hline 32700 & 267 & 397 & 18 & 34900 & 293 & 401 & 20 \\
\hline 32900 & 300 & 442 & 18 & 35000 & 301 & 469 & 8 \\
\hline 33000 & 293 & 400 & 19 & & & & \\
\hline
\end{tabular}



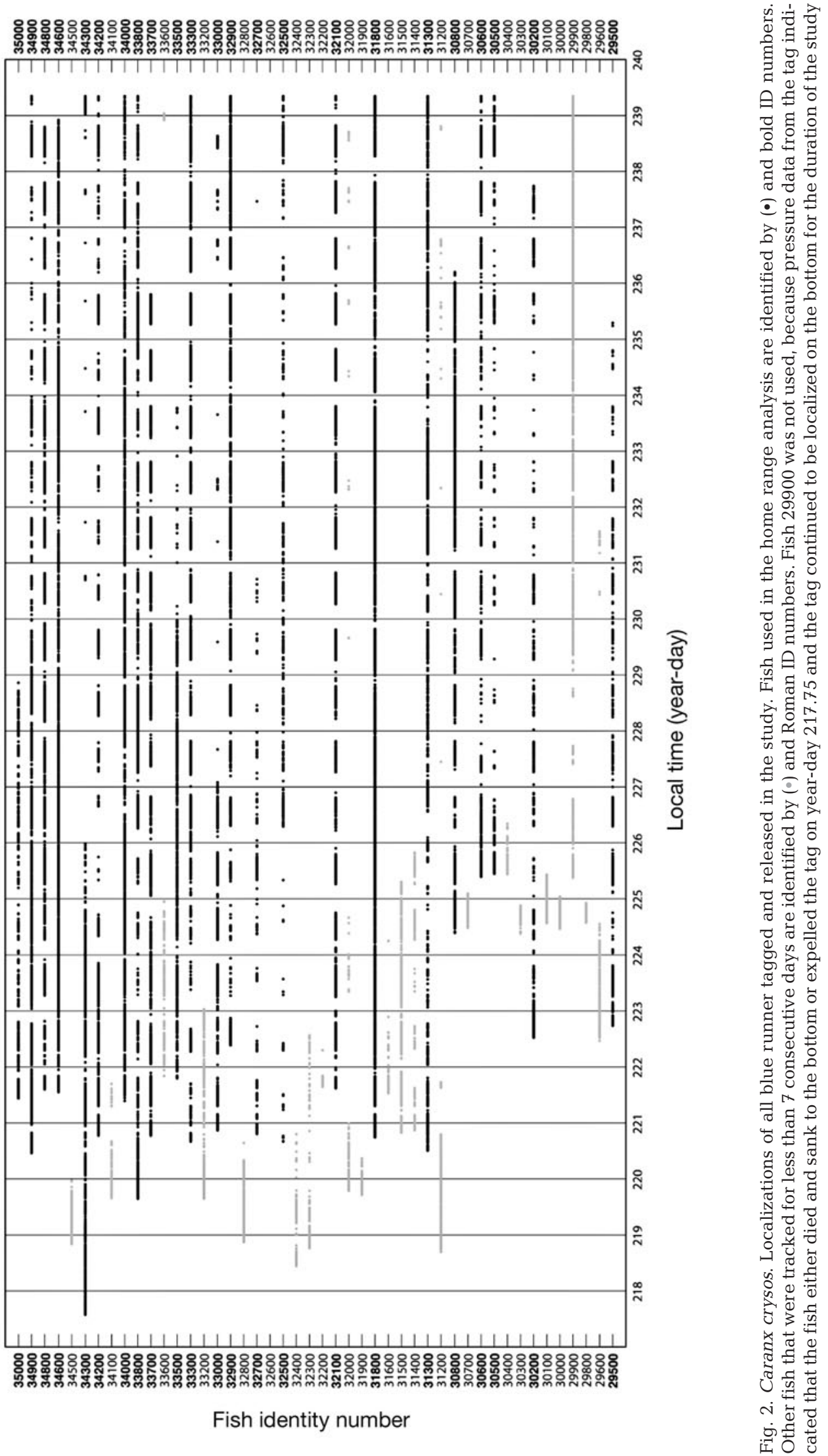

Fish identity number

ن 


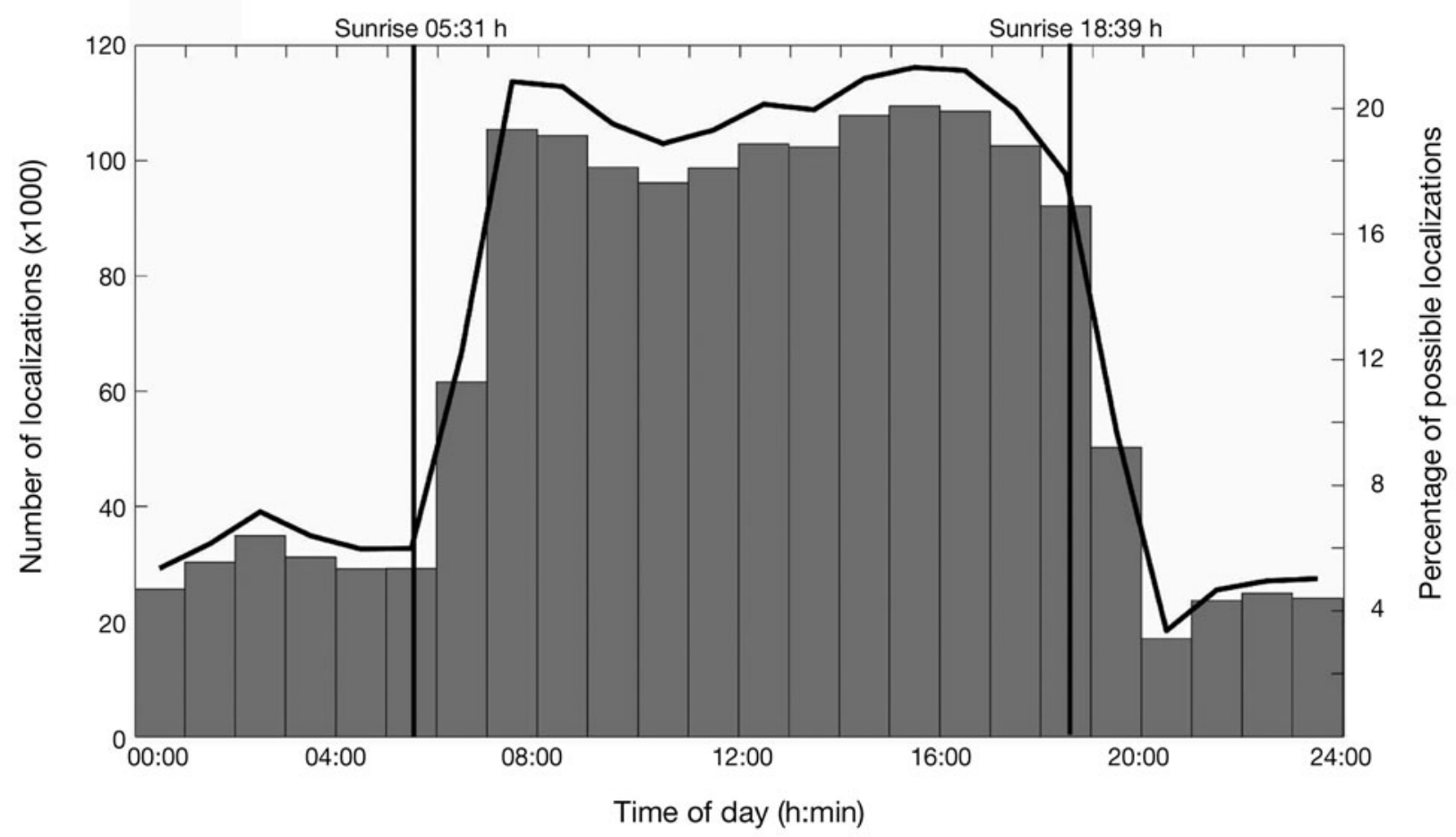

Fig. 3. The cumulative number of localizations during the entire study period (5 to 27 August 2005) broken down by $1 \mathrm{~h}$ periods. The line plot indicates the percentage of transmission events that resulted in valid localizations averaged over the study period.

The lines bisecting the histogram indicate sunrise and sunset times on 16 August 2005 (the middle of the study period)

platforms. Fish that were localized for less than $7 \mathrm{~d}$ or which disappeared from ST151 after periods of $7 \mathrm{~d}$ or more were not detected outside the ST151 array.

\section{Home range}

The mean size $( \pm \mathrm{SE})$ of the core home range was $2352( \pm 225) \mathrm{m}^{2}$ for all 23 fish over the entire study period, during which time it varied between 653 and $5307 \mathrm{~m}^{2}$. The mean size of the $95 \%$ range was $21204( \pm 1491) \mathrm{m}^{2}$, varying between 10246 and $36405 \mathrm{~m}^{2}$. Fish FL was significantly and positively correlated with the size of the core range; however, there was no significant correlation between the FL of the fish and the $95 \%$ ranges (Table 2 ).

When overall home ranges were broken down into $24 \mathrm{~h}$ periods (daily ranges), the mean core daily range of individual fish varied from 373 to $2202 \mathrm{~m}^{2}$, while the corresponding $95 \%$ daily range was between 3082 and $14333 \mathrm{~m}^{2}$. There was no correlation between the FL of the fish and the average size of their daily core home ranges, but there was a correlation between the FL of the fish and the average size of their $95 \%$ daily range (Table 2 ). A general linear model revealed a significant difference between the size of the core range and the $95 \%$ range when both the day of year and the individual fish were compared (Table 2). This indicates that the size of the ranges increased over time and that the home range areas for all tagged blue runner within the population varied significantly day to day over the course of the study.

The majority of fish showed fidelity for one or more platforms within the complex, and this fidelity ex-

Table 2. Caranx crysos. Results of the test of correlation between home range size and fish fork length (FL) and the general linear model test comparing home range size by day of year and individual fish. -: not applicable

\begin{tabular}{|lccc|}
\hline Correlations & $\mathrm{r}$ & $\mathrm{p}$ & $\mathrm{n}$ \\
\hline FL and 50\% range over entire study & 0.471 & 0.023 & 23 \\
FL and 95\% range over entire study & 0.321 & 0.135 & 23 \\
FL and mean size of daily 50\% range & 0.393 & 0.064 & 23 \\
FL and mean size of daily 95\% range & 0.524 & 0.010 & 23 \\
& & & \\
General linear model & $\mathrm{R}^{2}$ & $F$ & $\mathrm{p}$ \\
\hline 50\% range & 0.163 & - & - \\
95\% range & 0.231 & - & - \\
Day of year versus 50\% range & - & 14.273 & 0.000 \\
Day of year versus 95\% range & - & 20.476 & 0.000 \\
Individual fish versus 50\% range & - & 2.681 & 0.000 \\
Individual fish versus 95\% range & - & 4.085 & 0.000 \\
\hline
\end{tabular}


tended for days to over a week. There were 3 general patterns of site fidelity: fish that frequently restricted their core range to the area around the same platform in the complex over 7 or more days (e.g. Fig. 4A,B), fish that remained near the same structure for shorter periods of at least 3 to 6 consecutive days (e.g. Fig. 4C), and a few fish that changed the location of their core home range from day to day (e.g. Fig. 4D). Of the 23 fish studied here, 11 repeatedly located their core range near the same platform within the complex for at least 7 consecutive days. Fish 30200 provides an example of consistent site fidelity around the G-Deck platform over 8 d (16 to 23 August, Fig. 5). Nine fish demonstrated site fidelity to particular platforms for periods of 3 d. Only 3 fish showed no site fidelity, and the centroid of their core range was not located at one platform on successive days.

The core ranges of the fish with high site fidelity were not temporally consistent. That is, different fish, each displaying high site fidelity, were not all collocated at the same part of the complex on the same days, even though each appeared to favor a specific location in the complex (e.g. Fig. 6). Visual observations of blue runner schools around the complex indi- cated that there were many different concurrent schools that frequently coalesced and diverged. Although the core home ranges of some tagged fish overlapped on some days, daily differences in the locations of each core home range over the course of the study suggest that individual membership in schools varied over time.

Core and $95 \%$ home ranges were generally larger during the day and smaller at night. The mean daytime core range was between 404 and $2311 \mathrm{~m}^{2}$, and the mean nighttime core range was between 231 and $1744 \mathrm{~m}^{2}$. The mean daytime $95 \%$ range was between 3034 and $13722 \mathrm{~m}^{2}$, and the mean nighttime 95\% range was between 1299 and $9182 \mathrm{~m}^{2}$. Five fish had significant differences in the sizes of their daytime and nighttime core and $95 \%$ home ranges (Table 3). A single fish had a significant difference in the sizes of daytime and nighttime core ranges, while three additional fish had significant differences in the sizes of their daytime and nighttime $95 \%$ home ranges (Table 3). The overall differences in core range and $95 \%$ range when comparing day and night were both significantly different (Table 3). The differences in the sizes of the home ranges of the population of tagged fish tested

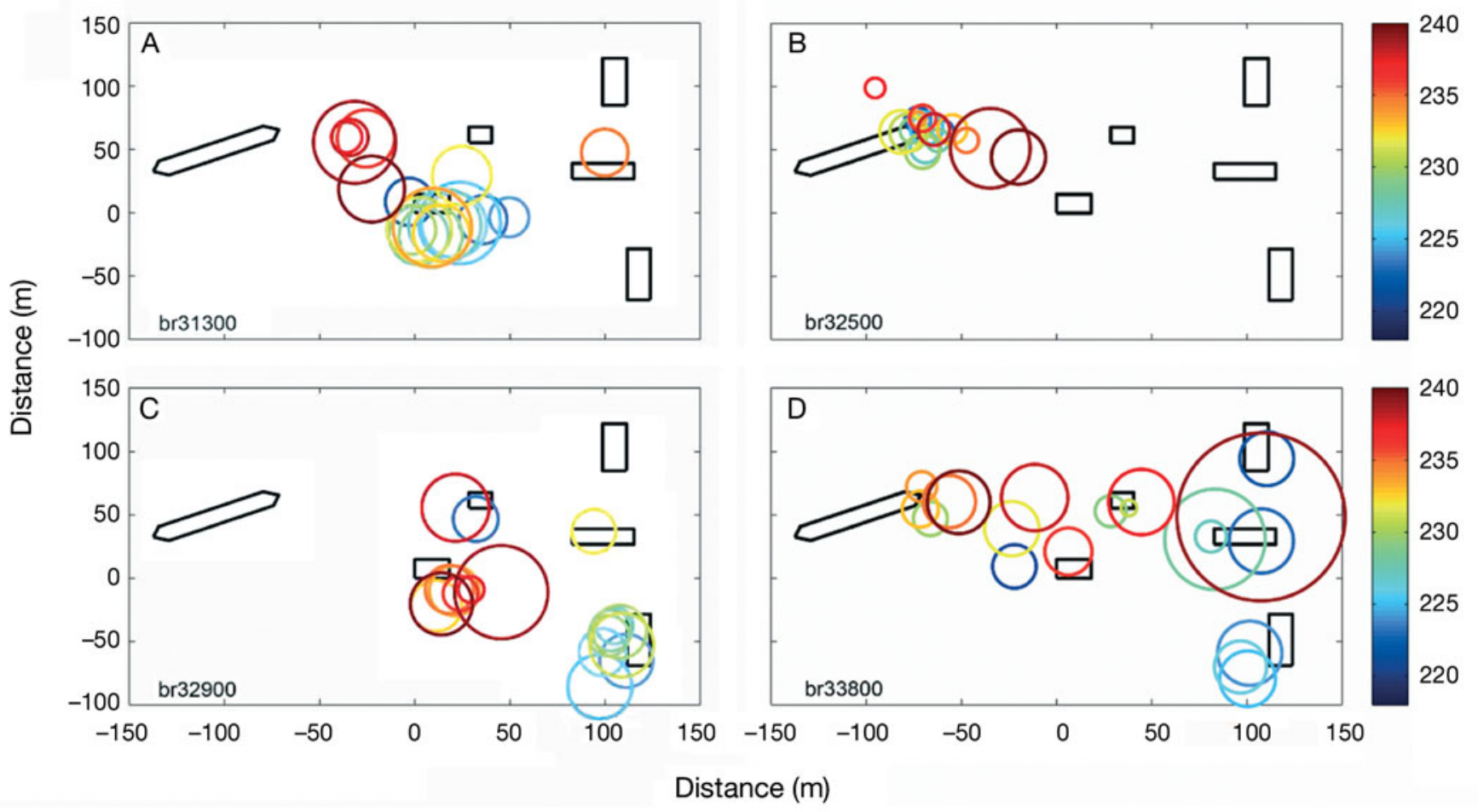

Fig. 4. Caranx crysos. Representative daily core home range patterns illustrated by 4 blue runner over the course of the study period. Each circle represents the location and size of the daily core range of a particular fish over the length of the study period. The colors of the circles indicate year-day. $(\mathrm{A}, \mathrm{B})$ Fish showing a preference for one particular platform; (C) fish showing a preference for different platforms in the complex over different periods; (D) fish showing no consistent preference for any particular platform 

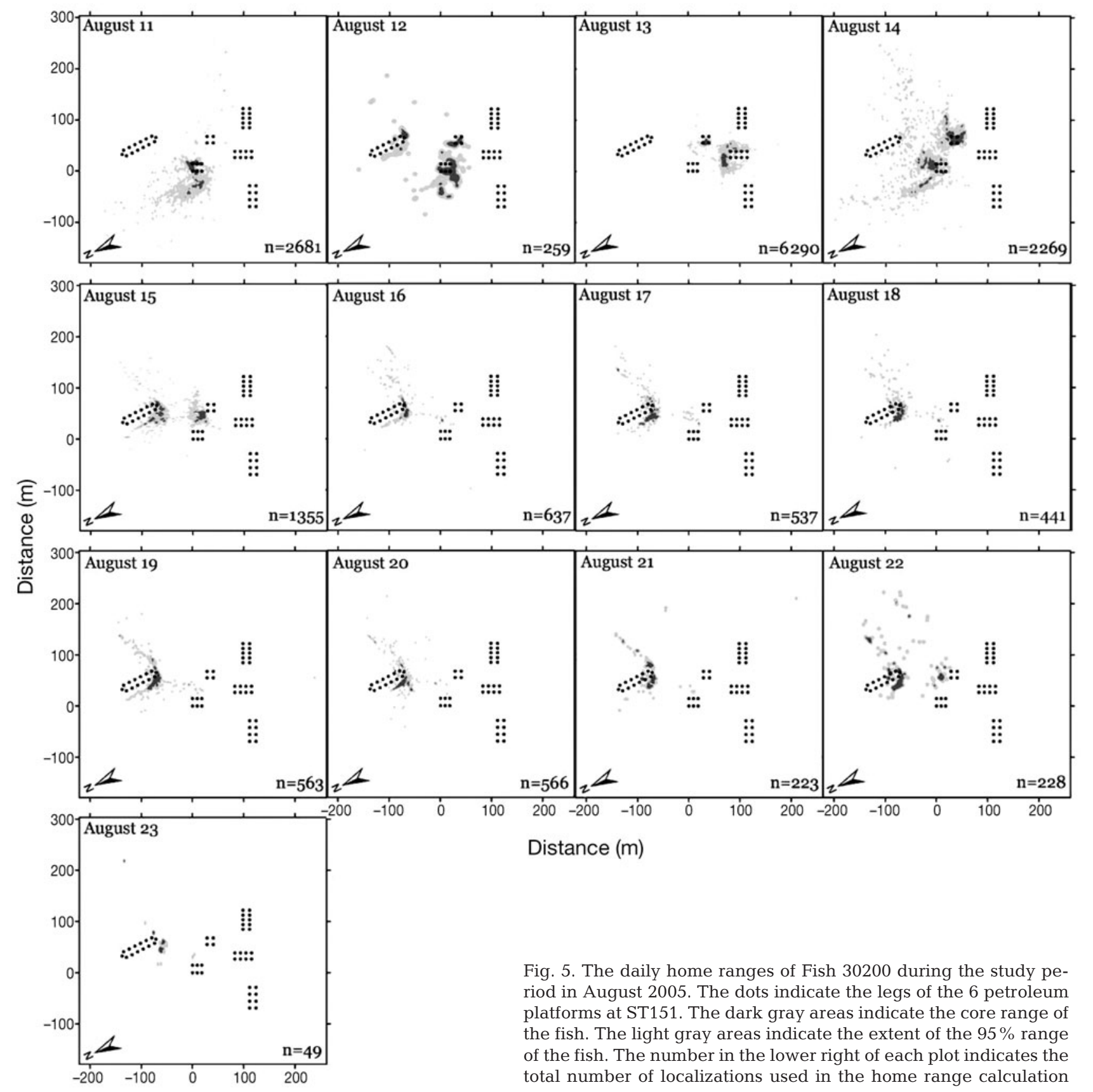

Fig. 5. The daily home ranges of Fish 30200 during the study period in August 2005. The dots indicate the legs of the 6 petroleum platforms at ST151. The dark gray areas indicate the core range of the fish. The light gray areas indicate the extent of the $95 \%$ range of the fish. The number in the lower right of each plot indicates the total number of localizations used in the home range calculation

using a multivariate general linear model (multivariate GLM) were explained by the variables used (fish ID and day of year) with low, but significant coefficients of determination (Table 4), with home range areas increasing over time.

Our detection envelope occupied an area of 5.62 ha (Fig. 7), which encompassed all of the platform structures in the complex. Detections extended beyond the platforms to the NW and E. The irregular shape of the detection envelope and well-defined boundaries are likely a consequence of the interactions between the platform structures and omnidirectional hydrophone detection sensitivities leading to masking of certain zones outside of the complex.

\section{DISCUSSION}

Acoustic telemetry enabled simultaneous localization of the positions of up to 46 tagged Caranx crysos with high temporal resolution. Individual fish were tracked for up to $23 \mathrm{~d}$. On the basis of battery life calculations, 


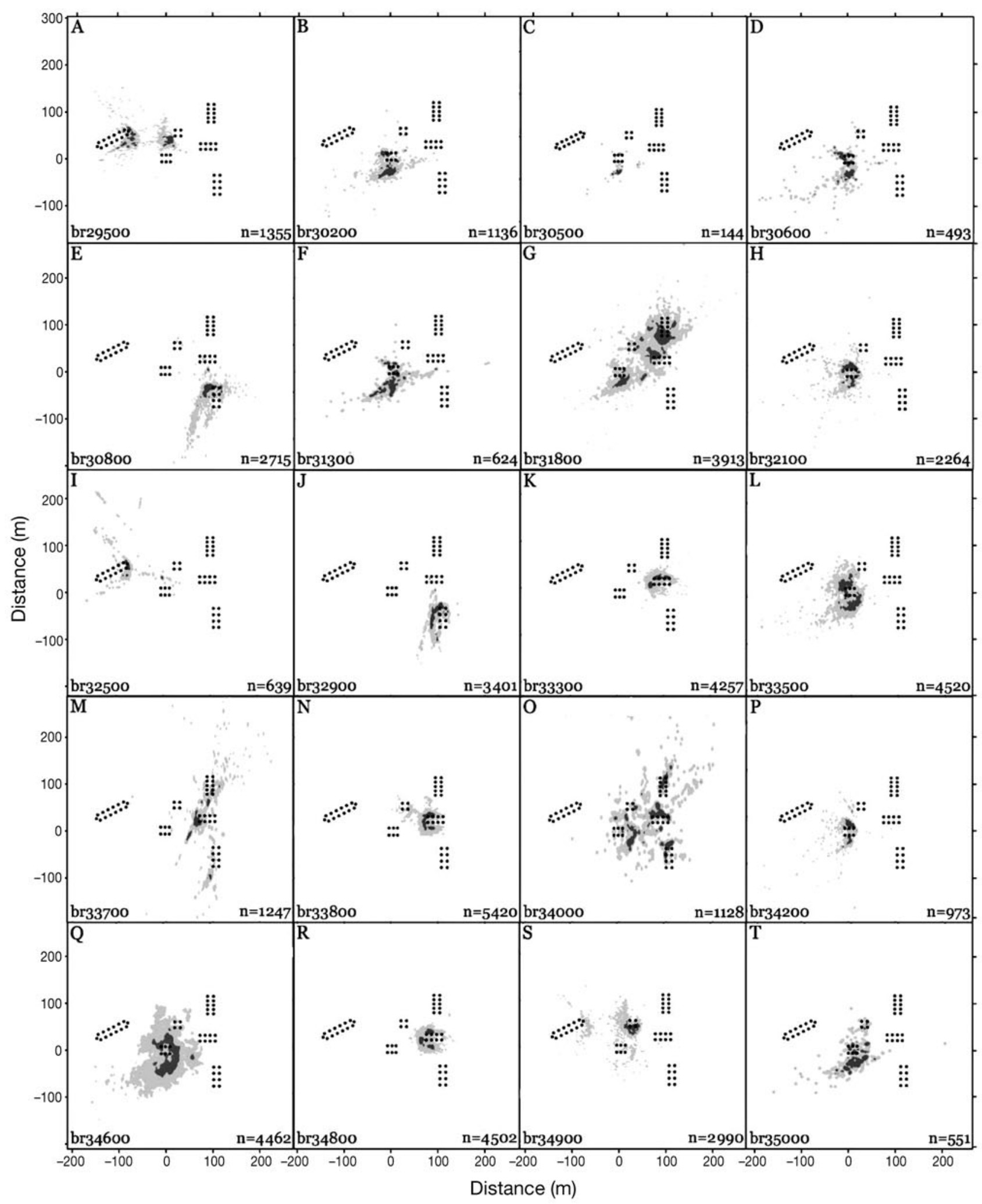

Fig. 6. Caranx crysos. The home ranges of 20 blue runner on 15 August 2005. The black dots indicate the legs of the 6 petroleum platforms at ST151. The dark gray areas indicate the core range of the fish. The light gray areas indicate the extent of the $95 \%$ range of the fish. The number in the lower right of each plot indicates the total number of localizations used in the home range calculation. (A) Fish 29500, (B) Fish 30200, (C) Fish 30500, (D) Fish 30600, (E) Fish 30800, (F) Fish 31300, (G) Fish 31800, (H) Fish 32100, (I) Fish 32500, (J) Fish 32900, (K) Fish 33300, (L) Fish 33500, (M) Fish 33700, (N) Fish 33800, (O) Fish 34000, (P) Fish 34200, 
Table 3. Caranx crysos. Results of the paired $t$-tests $(t)$ and Mann-Whitney $U$-tests $(U)$ to compare the day and night home range sizes of individual fish. ${ }^{*}$ Significant at $\alpha=0.05$

\begin{tabular}{|c|c|c|c|c|c|c|}
\hline \multirow{2}{*}{$\begin{array}{l}\text { Tag ID } \\
\text { code }\end{array}$} & \multicolumn{3}{|c|}{$-50 \%$ range -} & \multicolumn{3}{|c|}{ - $95 \%$ range } \\
\hline & $t$ & $U$ & $\mathrm{p}$ & $t$ & $U$ & $\mathrm{p}$ \\
\hline 29500 & & 50 & 0.137 & & 46 & 0.087 \\
\hline 30200 & & 64 & 0.567 & & 75 & 0.721 \\
\hline 30500 & 1.212 & & 0.292 & 1.378 & & 0.240 \\
\hline 30600 & & 63 & 0.649 & 2.118 & & 0.060 \\
\hline 30800 & 0.753 & & 0.469 & & 49 & 0.316 \\
\hline 31300 & & $92^{*}$ & 0.045 & & $76^{*}$ & 0.006 \\
\hline 31800 & & $79^{*}$ & 0.008 & & $62^{*}$ & 0.001 \\
\hline 32100 & & 129 & 0.610 & & 89 & 0.057 \\
\hline 32500 & & 99 & 0.126 & & $75^{*}$ & 0.017 \\
\hline 32700 & 0.010 & & 0.992 & 0.891 & & 0.402 \\
\hline 32900 & & 76 & 0.051 & & 89 & 0.142 \\
\hline 33000 & & $20^{*}$ & 0.046 & & $16^{*}$ & 0.019 \\
\hline 33300 & & 135 & 0.393 & & 122 & 0.206 \\
\hline 33500 & & $36^{*}$ & 0.039 & & $36^{*}$ & 0.039 \\
\hline 33700 & & 87 & 0.451 & & 89 & 0.505 \\
\hline 33800 & & $107^{*}$ & 0.032 & & $93^{*}$ & 0.010 \\
\hline 34000 & & 126 & 0.540 & & 97 & 0.106 \\
\hline 34200 & & 89 & 0.421 & & 65 & 0.072 \\
\hline 34300 & 0.099 & & 0.924 & 0.723 & & 0.490 \\
\hline 34600 & & $71^{*}$ & 0.032 & & 76 & 0.051 \\
\hline 34800 & & 131 & 0.658 & & $60^{*}$ & 0.003 \\
\hline 34900 & 1.987 & & 0.063 & $3.437^{*}$ & & 0.003 \\
\hline 35000 & 0.63 & & 0.952 & & 21 & 0.279 \\
\hline
\end{tabular}

Table 4. Caranx crysos. Results of a multivariate general linear model (GLM) comparing day and night home range sizes by day of year and individual fish. - - not applicable

\begin{tabular}{|c|c|c|c|c|c|c|}
\hline \multirow{2}{*}{$\begin{array}{l}\text { Multivariate } \\
\text { GLM }\end{array}$} & \multicolumn{3}{|c|}{ _ $50 \%$ range _- } & \multicolumn{3}{|c|}{ _ $95 \%$ range } \\
\hline & $\mathrm{R}^{2}$ & $F$ & $\mathrm{p}$ & $\mathrm{R}^{2}$ & $F$ & $\mathrm{p}$ \\
\hline Model results & 0.183 & - & - & 0.232 & - & - \\
\hline Day of year & - & 3.557 & 0.030 & - & 4.268 & 0.015 \\
\hline Individual fish & - & 1.795 & 0.002 & - & 2.354 & 0.000 \\
\hline
\end{tabular}

localizations could have continued for at least 7 more days had Hurricane Katrina not disrupted the study. These localizations enabled the movement patterns of pelagic fish to be evaluated within a large area (5.62 ha) encompassing 6 petroleum platforms in the Gulf. Twenty-three of the tagged fish were localized with sufficient consistency that their site fidelities and home ranges could be measured using fixed kernel analysis. The results suggest that pelagic C. crysos demonstrate a high degree of site fidelity and have measurable home ranges while in the proximity of artificial structures within the time frame of this study. This research indicates that schooling blue runner may establish a residence at offshore platforms for extended periods and supports observations that C. crysos is a regular part of the fish assemblage around offshore platforms.

\section{Home range}

Caranx crysos were closely associated with the petroleum platform complex. While the blue runner made excursions beyond the range of our detection envelope, the majority of the individuals routinely returned to the complex. No long-range movement was detected by the sentinel hydrophones on 3 outlying, unmanned platforms located several kilometers away from ST151. This may suggest that the manned platform complex is preferred habitat. We recognize that our small sample size, loss rate (mean of 0.84 fish $\mathrm{day}^{-1}$ ), and limited number of sentinel hydrophones at outlying platforms make it difficult to directly support this hypothesis; we do have additional data suggesting that the main complex is preferred by blue runner. Following the damage to the complex by Hurricane Katrina, we initiated a vessel-based study in 2006. Damage to the complex precluded reinstallation of the MAP_600 system in 2006. Instead, we deployed 10 autonomous data-logging hydrophones (WHS3050, Lotek Wireless) to subsurface parts of the main complex $(n=7)$ and 3 outlying platforms (one each at ST128R, ST151K, and ST152P, Fig. 1B). Of the 6 blue runner released at outlying platforms, 5 moved to the main complex within $17 \mathrm{~d}$ (Table 5). None of the blue runner released at the main complex were detected at unmanned satellite platforms.

Some of the fish exhibited site fidelity for the same platform within the complex for up to a week, though the particular platform varied among fish. Preference for a particular home range or territory is common when fish must defend a nesting (e.g. Lissaker \& Kvarnemo 2006) or mating site (e.g. Warner \& Schultz 1992), but it is a surprising finding for a schooling pelagic species. There are several possible explanations for why blue runner may show an affinity for a large manned platform complex such as ST151. Blue runner are reproductively active during the summer months (McKenney et al. 1958, Goodwin \& Finucane 1985), and they may utilize the platforms as a mating site. Proximity to the platforms may also permit access to elevated concentrations of planktonic food supplies, particularly at night when platform lights likely permit visual foraging in the upper half of the water column (Keenan et al. 2007). A third factor explaining their affinity for the complex may be that the 3-dimensional structure of the platforms provides refuge from larger predators. Visual observations indicate that when threatened, blue runner schools will quickly move into the structure beneath the platforms. While these factors could all explain why blue runner associate with platforms in general, none adequately explain why individual fish had home ranges that encompassed the same regions of the complex for several days at a time. 


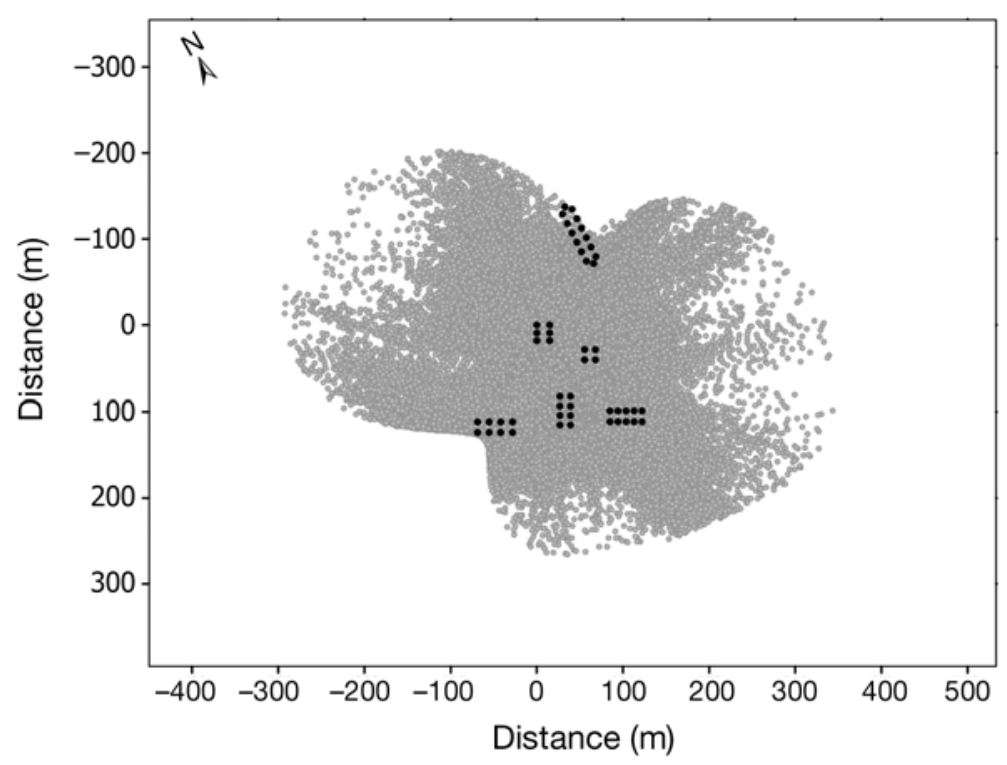

Fig. 7. Caranx crysos. The location solutions of all 23 blue runner during the study in August 2005. The total area encompassed by all the location solutions shown is 5.62 ha

Table 5. Caranx crysos. A listing of the blue runner tagged and released for monitoring in 2006. The table shows the date the fish was caught and surgically implanted with an acoustical tag, and the fork length (FL, mm) of the fish. Refer to Fig. 1 for locations of capture and release sites

\begin{tabular}{|lccc|}
\hline $\begin{array}{l}\text { Tag ID } \\
\text { code }\end{array}$ & $\begin{array}{c}\text { FL } \\
(\mathrm{mm})\end{array}$ & $\begin{array}{c}\text { Collection } \\
\text { location }\end{array}$ & $\begin{array}{c}\text { Release } \\
\text { location }\end{array}$ \\
\hline $\begin{array}{l}\text { August 21 } \\
30900\end{array}$ & 345 & ST151K & ST151K \\
34700 & 318 & ST151K & ST151K \\
34800 & 329 & ST151K & ST151K \\
34900 & 330 & ST151K & ST151K \\
35000 & 296 & ST151K & ST151K \\
35100 & 321 & ST151K & ST151K \\
35300 & 340 & ST151K & ST151 complex \\
35500 & 317 & ST151K & ST151 complex \\
35600 & 323 & ST151K & ST151 complex \\
$\begin{array}{l}\text { August 22 } \\
35900\end{array}$ & & & \\
35700 & 281 & ST151 complex & ST151 complex \\
36100 & 272 & ST151 complex & ST151 complex \\
36400 & 311 & ST151 complex & ST151 complex \\
36500 & 316 & ST134W & ST151 complex \\
August 24 & & & ST151 complex \\
36600 & 292 & ST151K & ST151 complex \\
36700 & 286 & ST151K & ST151 complex \\
37000 & 298 & ST151K & ST151 complex \\
36800 & 262 & ST151K & ST151 complex \\
36900 & 271 & ST151K & ST151 complex \\
\hline
\end{tabular}

Previous studies have used acoustic telemetry to demonstrate an affinity by pelagic fishes for fish aggregating devices (FADs). Previous studies using acoustic telemetry have shown that species of tuna and dolphinfish have remained at FADs for long periods (Table 6). None of these studies estimated the home ranges of these fish, but rather used telemetry to determine presence or absence of individual fish.

The use of fixed kernel estimation for home range has been a source of some controversy, primarily because the size of the home range may be overestimated due to spatial and temporal autocorrelation, particularly with small data sets (Downs 2008). Katajisto \& Moilanen (2006) used a method called time kernel estimation on brown bear data in an attempt to reduce the temporal autocorrelation of the data through resampling. However, the reported differences in home range size using time kernel estimators were actually slightly larger than those using fixed kernel estimation, though perhaps not significantly larger. Swihart \& Slade (1985) found that nonstatistical estimates of home range increased in accuracy with an increase in sample size, even if autocorrelation increased as well. The data set used in the present study is larger than the typical home range study, which would likely help to dampen the effects of autocorrelation.

By ignoring the depth component in our spatial analysis, we were able to utilize fixed kernel home range analysis tools developed for GIS applications such as ArcMap. Such tools have been developed primarily for the analysis of terrestrial animal home ranges. Given the increasing utilization of telemetry to study the locations and movements of aquatic organisms, there is a definite need for the development of 3-dimensional spatial analysis tools.

\section{Spatial movements}

In this study the movements of blue runner have been treated in a 2-dimensional context; however, the pressure data from the tags demonstrate that blue runner are typically located in the upper $10 \mathrm{~m}$ during the day and exhibit a reverse vertical migration to 20 to $25 \mathrm{~m}$ at dusk followed by an ascent at dawn. The effect of ignoring the depth of the fish when estimating its location within the detection envelope is small. For a fish located at the greatest distance from our hydrophones (approximately $300 \mathrm{~m}$ ), the positional error would be $\pm 0.16 \mathrm{~m}$ during the day (assuming $10 \mathrm{~m}$ depth) and $\pm 1.04 \mathrm{~m}$ at night (assuming $25 \mathrm{~m}$ depth). 
Table 6. Summary of previous studies on pelagic fish using acoustic telemetry. The table lists the species studied, the area where the research was conducted, the type of structure utilized, and the measured residence time (if determined). FADs = fish aggregating devices. -: no data

\begin{tabular}{|lcccc|}
\hline Species & \multicolumn{1}{c}{ Study area } & Structure & Residence time & Source \\
\hline Thunnus albacares & Tahiti (Pacific Ocean) & Buoys & $1-23 \mathrm{~d}$ & Girard et al. (2004) \\
Thunnus albacares & Okinawa Islands (Pacific Ocean) & FADs & $1-1282 \mathrm{~h}$ & Ohta \& Kakuma (2005) \\
Thunnus obesus & Okinawa Islands (Pacific Ocean) & FADs & $2-768 \mathrm{~h}$ & Ohta \& Kakuma (2005) \\
Thunnus albacares & Oahu, Hawaii (Pacific Ocean) & FADs & $0-150 \mathrm{~d}$ & Dagorn et al. (2007) \\
Thunnus obesus & Oahu, Hawaii (Pacific Ocean) & FADs & $0-10 \mathrm{~d}$ & Dagorn et al. (2007) \\
Thunnus albacares & Western Indian Ocean & Drifting FADs & - & Moreno et al. (2007) \\
Thunnus obesus & Western Indian Ocean & Drifting FADs & - & Moreno et al. (2007) \\
Katsuwonus pelamis & Western Indian Ocean & Drifting FADs & - & Moreno et al. (2007) \\
Coryphaenus hippurus & Western Indian Ocean & FADs & - & Girard et al. (2007) \\
\hline
\end{tabular}

For fishes closer to the array or at shallower depths, the errors would be smaller.

Fish depth also appeared to have an effect on our ability to detect them. When fish migrated down through the pycnocline, fewer transmissions from their tags would be received at our hydrophones located in the upper water column, because the pycnocline can act as a partial physical barrier to sound propagation (Siderius \& Porter 2004). This would explain why fewer transmission events were detected during the nighttime relative to the day.

A positive relationship between body size and home range size has been described for land mammals (Pagel et al. 1991), birds (Maurer et al. 1991), shrimp (Reaka 1980) and Cyprinella minnows (Taylor \& Gotelli 1994). Evidence for a similar relationship in our study was mixed. The relatively narrow size range of tagged blue runner may explain why clear evidence for a positive relationship between fish length and home range area was inconclusive.

The home range sizes of all tagged fish were significantly different among days and tended to increase in area through time. This increase in home range size may be related to a gradual recovery from tag implantation. In addition, the sizes of the home ranges of individual fish were significantly different. While some individual fish may move between platforms in the complex, the extent of their movements was consistent with a pattern of short excursions away from, and back to, the area of the complex that was contained in their home range. These excursions were likely centered around feeding activity, as blue runner were frequently observed feeding at the surface near platforms.

This study indicates that, at least for short-term periods of several weeks, blue runner do not exhibit substantial long-range movements, but instead remain in the general vicinity of the petroleum platform complex. Although extended absences from the complex were observed for some fish, they were frequently followed by returns to the complex. While it is possible that individual fish could have moved below the pycnocline, thereby masking their tag transmissions, it is unlikely that all transmissions $\left(900 \mathrm{~h}^{-1}\right.$ for the $0.25 \mathrm{~Hz}$ tags and $1800 \mathrm{~h}^{-1}$ for the $0.5 \mathrm{~Hz}$ tags) would have been blocked for extended periods. It is more likely that the missing individuals were beyond the detection envelope of our receivers on the ST151 complex (Fig. 7) or the unmanned satellite platforms. This may indicate excursions to waters away from platforms or to unmanned platforms that were not equipped with sentinel hydrophones. What is interesting is that these fish, which were collected and released at ST151, left the complex and then returned. How fish were able to navigate back to ST151 remains an open question. Platforms are acoustically noisy environments. Production activities, equipment-induced vibrations, vessel activity, and other sound sources all likely propagate into the water column. Tolimieri et al. (2000) found that sound can provide a navigational cue for pelagic fish larvae. It would be interesting to know whether blue runner use sounds to navigate back to the complex. Clearly more research would be required to test this hypothesis.

\section{Temporal activity}

During the day blue runner schools are frequently observed close to the individual platforms. Schools were usually found on the up-current side of the platform where they presumably intercept planktonic prey that are advected with the flow. The rotary nature of the tidal currents around platforms means that throughout the day, schools shift positions in response to the changing direction of the prevailing currents. Disturbances such as boats, predators, and helicopter traffic can result in fish darting into the platform structure at irregular intervals.

The diet of Caranx crysos at petroleum platforms shifts from zooplankton during the day to larger, 
more conspicuous micronekton and zooplankton at night (Keenan et al. 2003). Their shift towards larger, more conspicuous prey is consistent with feeding in reduced light intensities. The ST151 complex is illuminated with large floodlights that project light down into the water column. Keenan et al. (2007) demonstrated that the underwater light field around ST151 extended down below $25 \mathrm{~m}$ and that sufficient light was likely present to permit visual feeding by blue runner. The brightest illumination was located close to the platforms where the lights were concentrated.

If blue runner migrate downwards at night, it would be reasonable to expect that they would remain close to the platform structure in order to forage in well-illuminated water. If this were the case, then nocturnal home ranges would encompass a smaller area than those in the day. Support for this hypothesis was mixed. While 7 fish demonstrated significantly smaller nocturnal home ranges, the remaining fish showed no statistically significant difference in day versus night home range size. When blue runner forage in illuminated waters, they are also conspicuous prey for larger piscivores and must balance foraging activities with predation risk. It is reasonable to hypothesize that because blue runner are active and mobile at night, they periodically move close to platforms into regions of bright light to forage and then move back outside the periphery of the platform light halo in order to reduce their conspicuousness to visual predators, thus introducing variability into nocturnal home range size. Under such a scenario, equivalent-sized home ranges would be predicted.

\section{SUMMARY}

This is the first study using acoustic telemetry to determine the home range of pelagic fishes and to document the home range patterns of blue runner in the vicinity of artificial structures. Within the complex, many of the blue runner displayed site fidelity towards particular platforms within the complex, and this fidelity extended for periods of up to a week. Both the area encompassing the home range of individual blue runner and the number of localizations received were larger during the day than at night. While some of the blue runner detected during the day could not be detected for periods during the night, in most cases, such fish were localized within the complex the following morning. The artificial light field may have provided the blue runner detected within the platform complex during the night the ability to feed while remaining at a depth where light intensities are sufficiently low to reduce predator encounters.
Acknowledgements. The authors thank N. Geraldi, M. Alford, J. Bacon, K. Simonsen, M. Miller, and J. Blackburn for their help with field work. We appreciate the assistance of Lotek Wireless personnel, particularly M. Sisak and G. Niezgoda. The authors are also grateful to the Chevron Corporation and the crew of the Chevron South Timbalier 151 complex for all their help and cooperation. We express our gratitude to the 4 anonymous reviewers for their comments, which have helped to improve this article. This work was funded by the Minerals Management Service (Cooperative Agreement 1435-01-99CA-30951) and was completed as part of the requirements for the PhD degree for H.B. at Louisiana State University.

\section{LITERATURE CITED}

Baltz DM, Chesney EJ, Tarr MA, Kolok AS, Bradley MJ (2005) Toxicity and sublethal effects of methanol on swimming performance of juvenile Florida pompano. Trans Am Fish Soc 134:730-740

Blake RW, Chan KHS, Kwok EWY (2005) Finlets and the steady swimming performance of Thunnus albacares. J Fish Biol 67:1434-1445

Block BA, Teo SLH, Walli A, Boustany A and others (2005) Electronic tagging and population structure of Atlantic bluefin tuna. Nature 434:1121-1127

> Burt WH (1943) Territoriality and home range concepts as applied to mammals. J Mammal 24:346-352

> Dagorn L, Holland KN, Itano DG (2007) Behavior of yellowfin tuna (Thunnus albacares) and bigeye ( $T$. obesus) tuna in a network of fish aggregating devices (FADs). Mar Biol 151:595-606

Domeier ML, Kiefer D, Nasby-Lucas N, Wagschal A, O'Brien F (2005) Tracking Pacific bluefin tuna (Thunnus thynnus orientalis) in the northeastern Pacific with an automated algorithm that estimates latitude by matching sea-surface temperature data from satellites with temperature data from tags on fish. Fish Bull 103:292-306

Downs JA (2008) Network analysis of animal space-use patterns. PhD dissertation, Florida State University, Tallahassee, FL

Eristhee N, Oxenford HA (2001) Home range size and use of space by Bermuda chub Kyphosus sectatrix (L.) in two marine reserves in the Soufriere Marine Management Area, St Lucia, West Indies. J Fish Biol 59:129-151

Gallaway BJ, Lewbel GS (1982) The ecology of petroleum platforms in the northwestern Gulf of Mexico: a community profile. FWS 10BS-82/87. US Fish and Wildlife Service, Division of Biology Services, Washington, DC

Girard C, Benhamou S, Dagorn L (2004) FAD: Fish aggregating device or fish attracting device? A new analysis of yellowfin tuna movements around floating objects. Anim Behav 67:319-326

Girard C, Dagorn L, Tacquet M, Aumeeruddy R, Peignon C, Benhamou S (2007) Homing abilities of dolphinfish (Coryphaenus hippurus) displaced from fish aggregating devices (FADs) determined using ultrasonic telemetry. Aquat Living Resour 20:313-321

Goodwin JM IV, Finucane JH (1985) Reproductive biology of blue runner (Caranx crysos) from the eastern Gulf of Mexico. Northeast Gulf Sci 7:139-146

Hastings RW, Ogren LH, Mabry MT (1976) Observations on the fish fauna associated with offshore platforms in the northeastern Gulf of Mexico. Fish Bull 74:387-402

Holland KN, Lowe CG, Wetherbee BM (1996) Movements and dispersal patterns of blue trevally (Caranx melampygus) in a fisheries conservation zone. Fish Res 25:279-292 
Hymel MK, Baltz DM, Chesney EJ, Tarr MA, Kolok AS (2002) Swimming performance of juvenile Florida pompano exposed to ethylene glycol. Trans Am Fish Soc 131: $1152-1163$

Jadot C, Donnay A, Acolas ML, Cornet Y, Bégout Anras ML (2006) Activity patterns, home-range size, and habitat utilization of Sarpa salpa (Teleostei: Sparidae) in the Mediterranean Sea. ICES J Mar Sci 63:128-139

Jarque CM, Bera AK (1980) Efficient tests for normality, heteroscedasticity and serial independence of regression residuals. Economics Letters 6:255-259

> Jorgensen SJ, Kaplan DM, Klimley AP, Morgan SG, O'Farrell MR, Botsford LW (2006) Limited movement in blue rockfish Sebastes mystinus: internal structure of home range. Mar Ecol Prog Ser 327:157-170

Kasprzak RA (1998) Use of oil and gas platforms as habitat in Louisiana's artificial reef program. Gulf Mex Sci 16:37-45

Katajisto J, Moilanen A (2006) Kernel-based home range method for data irregular sampling intervals. Ecol Model 194:405-413

Keenan SF, Benfield MC, Shaw RF (2003) Zooplanktivory by blue runner Caranx crysos: a potential energetic subsidy to Gulf of Mexico fish populations at petroleum platforms. Am Fish Soc Symp 36:167-180

Keenan SF, Benfield MC, Blackburn JK (2007) Importance of the artificial light field around offshore platforms for the associated fish community. Mar Ecol Prog Ser 331:219-231

Kramer DL, Chapman MR (1999) Implications of fish home range size and relocation for marine reserve function. Environ Biol Fishes 55:65-79

Lembo G, Spedicato MT, Okland F, Carbonara P and others (2002) A wireless communication system for determining site fidelity of juvenile dusky groupers Epinephelus marginatus (Lowe, 1834) using coded acoustic transmitters. Hydrobiologia 483:249-257

Lissaker M, Kvarnemo C (2006) Ventilation or nest defense-parental care trade-offs in a fish with male care. Behav Ecol Sociobiol 60:864-873

Lyons J, Lucas MC (2002) The combined use of acoustic tracking and echosounding to investigate the movement and distribution of common bream (Abramis brama) in the River Trent, England. Hydrobiologia 483:265-273

Maurer BA, Ford HA, Rapoport EH (1991) Extinction rate, body size and avifaunal diversity. Acta XX Congress of International Ornithology, Vol 2. p 826-834

McKenney TW, Alexander EC, Voss GL (1958) Early development and larval distribution of the Carangid fish, Caranx crysos (Mitchill). Bull Mar Sci Gulf Caribb 8:167-200

Meyer CG, Honebrink RR (2005) Transintestinal expulsion of surgically implanted dummy transmitters by bluefin trevally - implications for long-term movement studies. Trans Am Fish Soc 134:602-606

MMS (2007) Platform locations in the Gulf $(3060,3063)$. United States Department of the Interior, Minerals Management Service, Gulf of Mexico Region

Moreno G, Dagorn L, Sancho G, Itano D (2007) Fish behaviour from fishers' knowledge: the case study of tropical tuna around fish aggregating devices (FADs). Can J Fish Aquat Sci 64:1517-1528

Editorial responsibility: Jon Hare,

Narragansett, Rhode Island, USA
Niezgoda G, Benfield MC, Sisak M, Anson P (2002) Tracking acoustic transmitters by code division multiple access (CDMA)-based telemetry. Hydrobiologia 483: $275-286$

Ohta I, Kakuma S (2005) Periodic behavior and residence time of yellowfin and bigeye tuna associated with fish aggregating devices around Okinawa Islands, as identified with automated listening stations. Mar Biol 146: 581-594

Pagel MP, May RM, Collie AR (1991) Ecological aspects of the geographical distribution and diversity of mammal species. Am Nat 137:791-815

Powell RA (2000) Animal home ranges and territories and home range estimators. In: Biotania L, Fuller TK (eds) Research techniques in animal ecology: controversies and consequences. Columbia University Press, New York, p 65-110

Reaka ML (1980) Geographic range, life history patterns, and body size in a guild of coral-dwelling mantis shrimps. Evolution 34:1019-1030

Robinson C, Pitcher T (1989) The influence of hunger and ration level on shoal density, polarization and swimming speed of herring, Clupea harengus L. J Fish Biol 34:631-633

Schroepfer RL, Szedlmayer ST (2006) Estimates of residence and site fidelity for red snapper Lutjanus campechanus on artificial reefs in the northeastern Gulf of Mexico. Bull Mar Sci 78:93-101

Siderius M, Porter M (2004) Impact of thermocline variability on underwater acoustic communications: results from KauaiEx. In: High Frequency Ocean Acoustics Conference Proceedings, La Jolla, CA, March 1-5, 2004. Springer-Verlag, New York, p 358-365

> Stanley DR, Wilson CA (1997) Seasonal and spatial variation in the abundance and size distribution of fishes associated with petroleum platforms in the northern Gulf of Mexico. Can J Fish Aquat Sci 54:1166-1176

Swihart RK, Slade NA (1985) Influence of sampling interval on estimates of home-range size. J Wildl Manag 49: $1019-1025$

Taylor CM, Gotelli NJ (1994) The macroecology of Cyprinella: correlates of phylogeny, body size and geographical range. Am Nat 144:549-569

Tolimieri N, Jeffs A, Montgomery JC (2000) Ambient sound as a cue for navigation by the pelagic larvae of reef fishes. Mar Ecol Prog Ser 207:219-224

> Tolimieri N, Andrews K, Williams G, Katz S, Levin PS (2009) Home range size and patterns of space use by lingcod, copper rockfish and quillback rockfish in relation to diel and tidal cycles. Mar Ecol Prog Ser 380:229-243

Topping DT, Lowe CG, Caselle JE (2005) Home range and habitat utilization of adult California sheephead, Semicossyphus pulcher (Labridae), in a temperate no-take marine reserve. Mar Biol 147:301-311

Warner RR, Schultz ET (1992) Sexual selection and male characteristics in the bluehead wrasse, Thalossoma bifasciatum, mating site acquisition, mating site defense, and female choice. Evolution 46:1421-1442

Zeller DC (1997) Home range and activity patterns of the coral trout Plectropomus leopardus (Serranidae). Mar Ecol Prog Ser 154:65-77

Submitted: April 29, 2008; Accepted: December 18, 2009 Proofs received from author(s): March 5, 2010 